\title{
Inhibiting Glycogen Synthase Kinase-3 Mitigates the Hematopoietic Acute Radiation Syndrome in Mice
}

\author{
Chang-Lung Lee ${ }^{\mathrm{a}, 1}$, William E. Lento ${ }^{\mathrm{c}, 1}$, Katherine D. Castle ${ }^{\mathrm{b}}$, Nelson J. Chaoc ${ }^{\mathrm{c}}$, and David \\ G. Kirsch ${ }^{a, b, 2}$ \\ aDepartment of Radiation Oncology, Duke University Medical Center, Durham, North Carolina \\ 27710 \\ bepartment of Pharmacology and Cancer Biology, Duke University Medical Center, Durham, \\ North Carolina 27710 \\ 'Division of Cellular Therapy, Department of Medicine, Duke University Medical Center, Durham, \\ North Carolina 27710
}

\begin{abstract}
Exposure to a nuclear accident or radiological attack can cause death from acute radiation syndrome (ARS), which results from radiation injury to vital organs such as the hematopoietic system. However, the U.S. Food and Drug Administration (FDA) has not approved any medical countermeasures for this specific purpose. With growing concern over nuclear terrorism, there is an urgent need to develop small molecule deliverables that mitigate mortality from ARS. One emerging modulator of hematopoietic stem/progenitor cell (HSPC) activity is glycogen synthase kinase-3 (GSK-3). The inhibition of GSK-3 has been shown to augment hematopoietic repopulation in mouse models of bone marrow transplantation. In this study, we performed an in vitro screen using irradiated bone marrow mononuclear cells (BM-MNCs) to test the effects of four GSK-3 inhibitors: CHIR99021; 6-Bromoindirubin-3'-oxime (BIO); SB415286; and SB216763. This screen showed that SB216763 significantly increased the frequency of c-Kit ${ }^{+} \mathrm{Lin}$ - Sca1 ${ }^{+}$(KLS) cells and hematopoietic colony-forming cells in irradiated BM-MNCs. Importantly, administration of a single dose of SB216763 to C57BL/6J mice by subcutaneous injection $24 \mathrm{~h}$ after total-body irradiation significantly improved hematopoietic recovery and mitigated hematopoietic ARS. Collectively, our results demonstrate that the GSK-3 inhibitor SB216763 is an effective medical countermeasure against acute radiation injury of the hematopoietic system.
\end{abstract}

\section{INTRODUCTION}

Radiation exposure from a nuclear accident or a radiological attack may cause death from acute radiation syndrome (ARS), which results from radiation injury to key organ systems such as the hematopoietic system $(1,2)$. Hematopoiesis is a radiation-sensitive process and

(C2014 by Radiation Research Society.

${ }^{2}$ Address for correspondence: Duke University Medical Center, Box 91006, Durham, NC 27708; david.kirsch@duke.edu.

${ }^{1}$ These authors contributed equally to this work. 
complications from radiation injury arise rapidly because radiation destroys both proliferating progenitor cells in the bone marrow and mature circulating cells in the peripheral blood $(3,4)$. Total-body irradiation (TBI) causes direct loss of hematopoietic cells by inducing the DNA damage response, which results in apoptosis, necrosis or cell senescence (5). After 2- to 8-Gy radiation exposure, damage to the hematopoietic compartment occurs, with pancytopenia and anemia evident after lower radiation doses and peripheral blood and hematopoietic stem/progenitor cell (HSPC) loss along with pancytopenia, marrow aplasia and spontaneous bleeding after higher doses of 4-8 Gy $(6,7)$.

There are currently no pharmaceuticals approved by the U.S. Food and Drug Administration (FDA) to mitigate hematopoietic ARS (8). With growing concern over the threat of a nuclear disaster leading to a mass casualty scenario, there is an urgent need to develop medical countermeasures that can be administered after exposure to radiation $(1,9)$. The Radiation and Nuclear Counter-measures Program at the National Institute of Allergy and Infectious Diseases (NIAID) has mandated that medical countermeasures must have efficacy when administered at least $24 \mathrm{~h}$ postirradiation. However, by $24 \mathrm{~h}$ after radiation exposure the majority of HSPCs that are sensitive to radiation-induced apoptosis will already be depleted (10). Therefore, it is imperative to develop novel medical countermeasures that function $24 \mathrm{~h}$ after exposure to improve regeneration of surviving HSPCs.

To address this unmet challenge, several groups including our own have systemically delivered protein ligands to mitigate hematopoietic ARS. For example, growth hormone and insulin-like growth factor 1 have both been shown to effectively mitigate lethal radiation injury in animal models $(11,12)$. More recently, epidermal growth factor and thrombospondin have been shown to mitigate hematopoietic ARS in mouse models $(13,14)$. Although ligand based strategies to activate signaling pathways at the receptor level are valuable proof-of-concept advances, small molecule pharmaceutical agents that target intracellular signaling components may be preferable for use in a mass casualty event because of their lower production costs and greater stability.

In an effort to investigate novel therapeutic targets to improve hematopoietic recovery after radiation injury we focused on glycogen synthase kinase-3 (GSK-3). GSK-3 is a multifunctional serine/threonine kinase (15) involved in multiple signaling pathways that regulate self-renewal, differentiation and the DNA damage response in hematopoietic cells (16-19). There are two forms of the kinase, GSK-3 $a$ and GSK-3 $\beta$, which are expressed from two highly homologous genes (20). Previous studies have shown that knockdown of both GSK-3 $\alpha$ and GSK-3 $\beta$ expands the number of phenotypic HSPCs in primary transplant recipients by promoting cell cycling of c- $\mathrm{Kit}^{+}$lineage ${ }^{-} \mathrm{Sca}-1^{+}$(KLS) cells (17). Moreover, serial administration of a GSK-3 inhibitor to primary transplant recipients improves hematopoietic reconstitution, recovery of neutrophils and megakaryocytes and overall survival (16).

Based on these findings, we hypothesized that transient inhibition of GSK-3 after TBI will mitigate acute radiation injury of the hematopoietic system by promoting repopulation of surviving HSPCs. In the current study, we performed an in vitro GSK-3 inhibitor screen using irradiated bone marrow mononuclear cells (BM-MNCs) and identified the GSK-3 
inhibitor SB216763 as a novel HSPC mitogen. Importantly, our data demonstrated that SB216763 effectively mitigates the hematopoietic ARS when administered $24 \mathrm{~h}$ after radiation exposure.

\section{MATERIALS AND METHODS}

Mice

All animal procedures for this study were approved by the Institutional Animal Care and Use Committee (IACUC) at Duke University. Eight- to 10-week-old C57BL/6J mice (Jackson Laboratory, Bar Harbor, ME) were used for the radiation studies. No supportive care was given to mice after irradiation. The health status of irradiated mice was monitored by trained laboratory personnel twice daily. The criteria for euthanasia (7) was based on two parameters: decreased activity and squinted/closed eyes on a scale of 1-3. A mouse receiving a score of 3 in either category or with a loss of more than $30 \%$ of body weight was considered moribund and was euthanized by carbon dioxide asphyxiation.

\section{Radiation Treatment}

For experiments shown in Figs. 1 and 2, BM-MNCs or mice were irradiated with a ${ }^{137} \mathrm{Cs}$ Shepherd irradiator at a dose rate of approximately $5.50 \mathrm{~Gy} / \mathrm{min}$. For experiments shown in Figs. 3 and 4, mice were irradiated with ionizing radiation using an X-RAD 320 Biological Irradiator (Precision X-ray Inc., North Branford, CT). Total-body irradiation was performed $50 \mathrm{~cm}$ from the radiation source with a dose rate of approximately $2.2 \mathrm{~Gy} / \mathrm{min}$ with $320 \mathrm{kVp}$ $\mathrm{X}$ rays, using $12.5 \mathrm{~mA}$ and a filter consisting of $2.5 \mathrm{~mm}$ aluminum and $0.1 \mathrm{~mm}$ copper. The dose rate was measured with an ion chamber by members of the Radiation Safety Division at Duke University.

\section{In Vitro GSK-3 Inhibitor Screen Using Irradiated Bone Marrow Mononuclear Cells}

To screen GSK-3 inhibitors in vitro, $1 \times 10^{5}$ BM-MNCs isolated by density centrifugation (Histopaque ${ }^{\circledR}$ 1077, Sigma-Aldrich LLC, St. Louis, MO) were plated in StemSpan media (StemCell Technologies, Vancouver, BC, Canada) supplemented with $100 \mathrm{ng} / \mathrm{mL}$ stem cell factor (SCF) and $50 \mathrm{ng} / \mathrm{mL}$ thrombopoetin (TPO) as previously described (21). Cells were then irradiated with 3 Gy $\gamma$ rays and $1 \mu M$ CHIR99021 (Stemgent, Cambridge, MA), 6Bromoindirubin-3'-oxime (BIO) (Cayman Chemical, Ann Arbor, MI), SB415286 or SB216763 (Tocris Bioscience, Bristol, UK) was added to the culture wells $1 \mathrm{~h}$ after radiation exposure. Dimethylsulfoxide (DMSO) was used as vehicle to dissolve these compounds. The cells were incubated for 7 days using standard culture conditions and then counted and stained for phenotypic makers of HSPCs. HSPCs were analyzed based on surface marker expression of c-Kit and Sca1, and low to negative expression of lineage markers (anti-mouse CD3, CD4, CD8, B220, CD11b, Gr-1 and Ter-119 antibodies) using an antibody cocktail as previously described (22). All antibodies were purchased from BD Pharmigen or eBioscience. The cell analysis was performed on a FACSCanto (BD Biosciences) and analyzed by FlowJo software (Tree Star Inc., Ashland, OR). 


\section{Quantification of Cell Apoptosis by Flow Cytometry}

To analyze apoptosis, $1 \times 10^{5} \mathrm{BM}-\mathrm{MNCs}$ isolated by density centrifugation (Histopaque 1077) were plated in StemSpan media (StemCell Technologies) supplemented with 100 $\mathrm{ng} / \mathrm{mL}$ SCF and $50 \mathrm{ng} / \mathrm{mL}$ TPO and irradiated with $3 \mathrm{~Gy}$. The cells were then treated with vehicle or SB216763 and cultured for $18 \mathrm{~h}$ before Annexin-V apoptosis assays were performed. The cultured cells were stained with KLS and then labeled with Annexin-V and 7-AAD (BD Biosciences) before analysis by flow cytometry.

\section{Analyzing Hematopoietic Stem/Progenitor Cells in the Bone Marrow}

Whole bone marrow cells were isolated from femurs and tibias by grinding the bones in hematopoietic stem cell (HSC) buffer [Hanks' balanced salt solution (HBSS) with $\mathrm{Ca}_{2}{ }^{+}$and $\mathrm{Mg}^{+}, 5 \%$ fetal bovine serum, $2 \mathrm{mM}$ EDTA]. Red blood cells (RBCs) were lysed using ACK lysing buffer (Lonza, Basel, Switzerland). The total cell number was counted with a Coulter counter (Beckman Coulter Inc., Brea, CA). Three million cells were blocked with a rat anti-mouse CD16/32 antibody (BD Pharmingen) and stained with PE-Cy5 conjugated lineage cocktail (anti-mouse CD3, CD4, CD8, B220, CD11b, Gr-1 and Ter-119 antibodies), PE conjugated anti-mouse Sca1 and APC conjugated anti-mouse c-Kit (eBioscience). Dead cells were excluded by staining with 7-AAD (BD Pharmigen). Data were collected from 1 million single cells by FACSCanto (BD Biosciences) and analyzed by FlowJo software.

For colony-forming cell (CFC) assays, $2 \times 10^{4}$ RBC-depleted whole bone marrow cells were plated in MethoCult GF 3434 (StemCell Technologies) and colonies were counted 7 days later.

\section{Statistics}

Data are presented as mean \pm SEM. Where variance was heterogeneous, data were logtransformed prior to applying statistical tests. Student's $t$ test (two-tailed) was performed to compare the means of two groups. For the acute radiation syndrome studies, Kaplan-Meier analysis was performed followed by the log-rank test. Statistical significance was assumed at $P<0.05$. GraphPad Prism 5 (GraphPad Software Inc., La Jolla, CA) was used for the calculation of statistics.

\section{RESULTS}

\section{In Vitro Screen Using Bone Marrow Mononuclear Cells Identifies SB216763 as a Candidate Medical Countermeasure Against Hematopoietic Acute Radiation Syndrome}

To investigate the effect of pharmacologically blocking GSK-3 after irradiation on regeneration of surviving HSPCs, we performed an in vitro GSK-3 inhibitor screen using BM-MNCs cultured in serum-free insulin containing media (21). BM-MNCs isolated from C57BL/6J mice were irradiated with $3 \mathrm{~Gy} \gamma$ rays in vitro. BM-MNCs were treated $1 \mathrm{~h}$ after irradiation with $1 \mu M$ of different chemical inhibitors of GSK-3, including CHIR99021, 6Bromoindirubin-3'-oxime (BIO), SB415286 and SB216763. All four compounds have low nanomolar $\mathrm{IC}_{50}$ values for GSK-3 (range 5-76 $\mathrm{nM}$ ) (23). After 7 days of culture, irradiated BM-MNCs treated with CHIR99021 and BIO had increased total cellularity (Fig. 1A). However, analysis of KLS immunophenotype (24) by flow cytometry (Fig. 1B) revealed 
that treatment with these two compounds markedly diminished the frequency of c-Kit ${ }^{+} \mathrm{Lin}^{-}$ $\mathrm{Sca}^{-}$(KL) cells, which comprise oligopotent myeloid progenitors (Fig. 1C). In contrast, treatment with SB216763 maintained the KL cell population and significantly increased the frequency of KLS cells, which are enriched for multipotent HSPCs (Fig. 1D).

To further characterize whether treating BM-MNCs with SB216763 after irradiation increases the frequency of functional hematopoietic progenitors, we harvested irradiated BM-MNCs 10 days after culture with vehicle or SB216763 to perform hematopoietic CFC assays. Consistent with the results from phenotypic analysis by flow cytometry, treatment with SB216763 after 3 Gy $\gamma$ rays significantly increased the frequency of CFCs in BMMNCs (Fig. 1E). Interestingly, treatment with SB216763 after 3 Gy $\gamma$ rays did not significantly affect apoptosis in KL or KLS cells based on Annexin-V and 7-AAD staining $18 \mathrm{~h}$ after irradiation (Fig. 1F). Together, our results from the in vitro GSK-3 inhibitor screen show that SB216763 increases the frequency of functional hematopoietic progenitors in irradiated BM-MNCs and suggest that of the compounds tested, SB216763 may function best as a mitigator against hematopoietic radiation injury in vivo.

To validate our results from the in vitro screen in vivo, we administered a single dose of BIO (30 mg/kg), SB415286 (30 mg/kg) or SB216763 (20 mg/kg) to C57BL/6J mice by intraperitoneal injection $1 \mathrm{~h}$ after $8.5 \mathrm{~Gy}$ TBI using $\gamma$ rays. This radiation dose causes hematopoietic ARS in $100 \%$ of mice within 30 days $\left(\mathrm{LD}_{100 / 30}\right)$. Consistent with our results from the in vitro screen, administration of BIO, which decreased the frequency of KL cells in irradiated BM-MNCs (Fig. 1C), did not mitigate hematopoietic ARS (Fig. 2A). Although administration of SB415286 provided a marginal increase in the 30 day survival after TBI (Fig. 2B), administration of SB216763 $1 \mathrm{~h}$ after 8.5 Gy TBI markedly decreased mortality from hematopoietic ARS and increased survival to approximately $60 \%$ on day 30 (Fig. 2C). Collectively, our data show that SB216763 functions after irradiation to promote regeneration of hematopoietic progenitors in vitro and to mitigate hematopoietic ARS when administered $1 \mathrm{~h}$ after TBI. These results suggest that SB216763 is a promising medical countermeasure that can effectively mitigate hematopoietic ARS after TBI.

\section{Subcutaneous Administration of SB216763 to Mice 24 Hours after Total-Body Irradiation Improves Repopulation of Hematopoietic Progenitors In Vivo}

To investigate if SB216763 could augment the recovery of HSPCs from radiation injury when given $24 \mathrm{~h}$ after TBI by a route that does not require clinical support and medical training, we subcutaneously administered a single dose of $20 \mathrm{mg} / \mathrm{kg} \mathrm{SB} 216763$ or vehicle to C57BL/6J mice $24 \mathrm{~h}$ after a sublethal dose of $5 \mathrm{~Gy}$ TBI using X rays. We then assessed HSPCs repopulation on days 8 and 15 after irradiation. Administration of SB216763 $24 \mathrm{~h}$ after irradiation did not increase the number of whole bone marrow cells 8 and 15 days after TBI (Fig. 3A). However, analysis of KLS immunophenotype by flow cytometry (Fig. 3B) showed that SB216763 treatment significantly increased the frequency of KL and KLS cells 8 and 15 days after TBI (Fig. 3C and D). In addition, SB216763 treatment significantly increased the frequency of bone marrow CFCs at day 15 after irradiation (Fig. 3E). Together, these results demonstrate that $24 \mathrm{~h}$ after TBI, subcutaneous administration of 
SB216763 significantly improves recovery of hematopoietic progenitors from radiation injury.

\section{Subcutaneous Administration of SB216763 to Mice 24 Hours after Total-Body Irradiation Mitigates Hematopoietic Acute Radiation Syndrome}

To evaluate the efficacy of SB216763 for the treatment of hematopoietic ARS when given $24 \mathrm{~h}$ after irradiation, we subcutaneously administered a single dose of $20 \mathrm{mg} / \mathrm{kg} \mathrm{SB} 216763$ to C57BL/6J mice $24 \mathrm{~h}$ after TBI with 6.5-7.5 Gy X rays. Remarkably, after exposure to 6.5 Gy $\left(\mathrm{LD}_{40 / 30}\right)$ and $6.75 \mathrm{~Gy}\left(\mathrm{LD}_{90 / 30}\right) \mathrm{TBI}$, a single injection of $20 \mathrm{mg} / \mathrm{kg}$ of SB216763 $24 \mathrm{~h}$ after irradiation significantly improved the 30 day survival of mice by 20 to $25 \%$ (Fig. $4 \mathrm{~A}$ and B). In addition, administration of SB216763 $24 \mathrm{~h}$ after TBI at a $\mathrm{LD}_{100 / 30}$ dose of $7 \mathrm{~Gy}$ significantly increased the mean survival time from 13 days to 22.5 days (Fig. 4C), whereas the mitigation effect of SB216763 was not observed in mice that were exposed to $7.5 \mathrm{~Gy}$ $\left(\mathrm{LD}_{100 / 15}\right)$ TBI (Fig. 4D). Taken together, these results demonstrate that SB216763 is an effective medical countermeasure that functions $24 \mathrm{~h}$ after TBI to improve hematopoietic regeneration after acute radiation injury.

\section{DISCUSSION}

Here we show the data from an in vitro GSK-3 inhibitor screen using irradiated BM-MNCs. This screen identified the ability of SB216763, a small molecule derivative of malemide, to significantly increase the frequency of KLS cells and CFCs in BM-MNCs (Fig. 1D and E). In addition, we extended the results from the in vitro screen in C57BL/6J mice and showed that among the GSK inhibitors we tested, SB216763 is the most potent compound to mitigate hematopoietic ARS (Fig. 2). Importantly, our results demonstrate that a single subcutaneous injection of $20 \mathrm{mg} / \mathrm{kg} \mathrm{SB} 21676324 \mathrm{~h}$ after TBI improved repopulation of hematopoietic progenitors (Fig. 3) and mitigated hematopoietic ARS after exposure to totalbody $\mathrm{X}$ irradiation with $6.5 \mathrm{~Gy}\left(\mathrm{LD}_{40 / 30}\right)$ to $7 \mathrm{~Gy}\left(\mathrm{LD}_{100 / 30}\right)$ (Fig. 4). However, we did not observe an increase in overall survival of mice after $7.5 \mathrm{~Gy}\left(\mathrm{LD}_{100 / 15}\right) \mathrm{TBI}$, suggesting that SB216763 is only effective to mitigate ARS induced by radiation doses that are below a certain threshold (e.g., $\mathrm{LD}_{100 / 30}$ ).

Recent studies have revealed a crucial role of GSK-3 in controlling the intrinsic pathway of apoptosis $(19,25)$. Blocking this pathway dramatically increases radiation resistance in various cell types including hematopoietic cells (26). It has been shown that pretreatment with SB216763 decreased radiation-induced apoptosis in the small intestine (27) and the hippocampus (28). In addition, C57BL/6J mice treated with SB415286 before 8 or 12 Gy TBI were significantly protected from ARS (27). Interestingly, a recent study suggests that pretreatment with SB216763 decreases the overall survival of mice after 5, 7 or 9 Gy TBI, possibly by augmenting radiation-induced apoptosis, but the dose of SB216763 administered to mice in this study was not clearly stated (29). However, in our experiments treating BMMNCs with SB216763 after irradiation did not affect apoptosis of KLS or KL cells (Fig. 1F). Therefore, our data suggest that SB216763 functions as a radiation mitigator by mechanisms that are independent of blocking radiation-induced apoptosis. 
The improved recovery of irradiated HSPCs after SB216763 treatment could be attributed to multiple mechanisms. Studies using mouse and human HSPCs indicate that inhibition of GSK-3 promotes HSPC repopulation by activating downstream signaling pathways including Hedgehog, Notch and Wnt (16). Indeed, a previous study and our unpublished work indicate a crucial role for $\mathrm{Wnt} / \beta$-catenin signaling in hematopoietic regeneration after chemotherapy (30) or radiation injury. ${ }^{3}$ In addition, there are emerging data showing that GSK-3 inhibition may also modulate the inflammatory response by regulating Toll-like receptor (TLR) signal transduction $(31,32)$. TLRs play a critical role in controlling the innate immune response (33). When human peripheral blood mononuclear cells were treated with SB216763 and stimulated with specific agonists to TLR2, TLR4, TLR5 or TLR9, there was a marked reduction in proinflammatory cytokines such as TNF and IL-1 $\beta$. Conversely, the anti-inflammatory cytokine IL-10 was substantially increased (32). Thus, inhibition of GSK-3 may tip the balance between TLR-mediated pro- and anti-inflammatory responses. Given that agonists of TLR5 (CBL502) (34), TLR2 (35) and TLR9 (36) can mitigate the ARS, it is possible that GSK-3 inhibitors may also function as mitigators of radiation injury at least in part by modulating TLR signaling. Therefore, further studies investigating the mechanism of action of SB216763 as a medical countermeasure against hematopoietic ARS are warranted.

In summary, our results demonstrate that the GSK-3 inhibitor SB216763 effectively mitigates hematopoietic ARS in mice when subcutaneously administered $24 \mathrm{~h}$ after totalbody irradiation. These data support the need for further investigation of GSK-3 inhibitors in mitigating hematopoietic acute radiation syndrome and suggest that such compounds may have clinical utility in the event of a radiologic disaster.

\section{Acknowledgments}

These studies were supported by NIAID R01 AI080488 (DGK) and U19 AI 067798 (NJC).

\section{References}

1. Williams JP, Brown SL, Georges GE, Hauer-Jensen M, Hill RP, Huser AK, et al. Animal models for medical countermeasures to radiation exposure. Radiat Res. 2010; 173:557-78. [PubMed: 20334528]

2. Waselenko JK, MacVittie TJ, Blakely WF, Pesik N, Wiley AL, Dickerson WE, et al. Medical management of the acute radiation syndrome: recommendations of the Strategic National Stockpile Radiation Working Group. Ann Intern Med. 2004; 140:1037-51. [PubMed: 15197022]

3. Dainiak N. Hematologic consequences of exposure to ionizing radiation. Exp Hematol. 2002; 30:513-28. [PubMed: 12063018]

4. Mauch P, Constine L, Greenberger J, Knospe W, Sullivan J, Liesveld JL, et al. Hematopoietic stem cell compartment: acute and late effects of radiation therapy and chemotherapy. Int J Radiat Oncol Biol Phys. 1995; 31:1319-39. [PubMed: 7713791]

5. Bondar T, Medzhitov R. p53-mediated hematopoietic stem and progenitor cell competition. Cell Stem Cell. 2010; 6:309-22. [PubMed: 20362536]

6. Dainiak N, Waselenko JK, Armitage JO, MacVittie TJ, Farese AM. The hematologist and radiation casualties. Hematology. 2003; 2003:473-96. [PubMed: 14633795]

${ }^{3}$ Lento WE, Ito T, Zhao C, Harris JR, Jiang C, Owzar K, et al. Loss of beta-catenin triggers oxidative stress and impairs hematopoietic regeneration in vivo. (in press, Genes and Development) 
7. Plett PA, Sampson CH, Chua HL, Joshi M, Booth C, Gough A, et al. Establishing a murine model of the hematopoietic syndrome of the acute radiation syndrome. Health Phys. 2012; 103:343-55. [PubMed: 22929467]

8. Xiao M, Whitnall MH. Pharmacological countermeasures for the acute radiation syndrome. Curr Mol Pharmacol. 2009; 2:122-33. [PubMed: 20021452]

9. Mettler FA, Voelz GL. Major radiation exposure-what to expect and how to respond. N Engl J Med. 2002; 346:1554-61. [PubMed: 12015396]

10. Wang Y, Schulte BA, LaRue AC, Ogawa M, Zhou D. Total body irradiation selectively induces murine hematopoietic stem cell senescence. Blood. 2006; 107:358-66. [PubMed: 16150936]

11. Chen BJ, Deoliveira D, Spasojevic I, Sempowski GD, Jiang C, Owzar K, et al. Growth hormone mitigates against lethal irradiation and enhances hematologic and immune recovery in mice and nonhuman primates. PLoS ONE. 2010; 5:e11056. [PubMed: 20585403]

12. Zhou D, Deoliveira D, Kang Y, Choi SS, Li Z, Chao NJ, et al. Insulin-like growth factor 1 mitigates hematopoietic toxicity after lethal total body irradiation. Int J Radiat Oncol Biol Phys. 2013; 85:1141-48. [PubMed: 23021438]

13. Doan PL, Himburg HA, Helms K, Russell JL, Fixsen E, Quarmyne M, et al. Epidermal growth factor regulates hematopoietic regeneration after radiation injury. Nat Med. 2013; 19:295-304. [PubMed: 23377280]

14. Geiger H, Pawar SA, Kerschen EJ, Nattamai KJ, Hernandez I, Liang HPH, et al. Pharmacological targeting of the thrombomodulin-activated protein $\mathrm{C}$ pathway mitigates radiation toxicity. Nat Med. 2012; 18:1123-29. [PubMed: 22729286]

15. Doble BW. GSK-3: tricks of the trade for a multi-tasking kinase. J Cell Sci. 2003; 116:1175-86. [PubMed: 12615961]

16. Trowbridge JJ, Xenocostas A, Moon RT, Bhatia M. Glycogen synthase kinase-3 is an in vivo regulator of hematopoietic stem cell repopulation. Nat Med. 2006; 12:89-98. [PubMed: 16341242]

17. Huang J, Zhang Y, Bersenev A, O'Brien WT, Tong W, Emerson SG, et al. Pivotal role for glycogen synthase kinase-3 in hematopoietic stem cell homeostasis in mice. J Clin Invest. 2009; 119:3519-29. [PubMed: 19959876]

18. Ko KH, Holmes T, Palladinetti P, Song E, Nordon R, O’Brien TA, et al. GSK-3beta inhibition promotes engraftment of ex vivo-expanded hematopoietic stem cells and modulates gene expression. Stem cells. 2011; 29:108-18. [PubMed: 20960517]

19. Charvet C, Wissler M, Brauns-Schubert P, Wang SJ, Tang Y, Sigloch FC, et al. Phosphorylation of Tip60 by GSK-3 determines the induction of PUMA and apoptosis by p53. Molecular Cell. 2011; 42:584-96. [PubMed: 21658600]

20. Woodgett J. Molecular cloning and expression of glycogen synthase kinase-3/factor A. EMBO. 1990; 9:2431-38.

21. Perry JM, He XC, Sugimura R, Grindley JC, Haug JS, Ding S, et al. Cooperation between both $\mathrm{Wnt} /\{$ beta $\}$-catenin and PTEN/PI3K/Akt signaling promotes primitive hematopoietic stem cell self-renewal and expansion. Genes Dev. 2011; 25:1928-42. [PubMed: 21890648]

22. Zhao C, Blum J, Chen A, Kwon HY, Jung SH, Cook JM, et al. Loss of [beta]-catenin impairs the renewal of normal and CML stem cells in vivo. Cancer Cell. 2007; 12:528-41. [PubMed: 18068630]

23. Meijer L, Flajolet M, Greengard P. Pharmacological inhibitors of glycogen synthase kinase 3. Trends Pharmacol Sci. 2004; 25:471-80. [PubMed: 15559249]

24. Okada S, Nakauchi H, Nagayoshi K, Nishikawa S, Miura Y, Suda T. In vivo and in vitro stem cell function of c-kit- and Sca-1-positive murine hematopoietic cells. Blood. 1992; 80:3044-50. [PubMed: 1281687]

25. Jacobs KM, Bhave SR, Ferraro DJ, Jaboin JJ, Hallahan DE, Thotala D. GSK-3beta: A bifunctional role in cell death pathways. Int J Cell Biol. 2012; 2012930710.

26. Kirsch DG, Santiago PM, di Tomaso E, Sullivan JM, Hou WS, Dayton T, et al. p53 controls radiation-induced gastrointestinal syndrome in mice independent of apoptosis. Science. 2010; 327:593-6. [PubMed: 20019247] 
27. Thotala DK, Geng L, Dickey AK, Hallahan DE, Yazlovitskaya EM. A new class of molecular targeted radioprotectors: GSK-3beta inhibitors. Int J Radiat Oncol Biol Phys. 2010; 76:557-65. [PubMed: 20117291]

28. Thotala DK, Hallahan DE, Yazlovitskaya EM. Inhibition of glycogen synthase kinase 3 beta attenuates neurocognitive dysfunction resulting from cranial irradiation. Cancer Res. 2008; 68:5859-68. [PubMed: 18632640]

29. Li B, Zhang C, He F, Liu W, Yang Y, Liu H, et al. GSK-3beta inhibition attenuates LPS-induced death but aggravates radiation-induced death via down-regulation of IL-6. Cell Physiol Biochem. 2013; 32:1720-8. [PubMed: 24356466]

30. Congdon KL, Voermans C, Ferguson EC, DiMascio LN, Uqoezwa M, Zhao C, et al. Activation of Wnt signaling in hematopoietic regeneration. Stem Cells. 2008; 26:1202-10. [PubMed: 18308947]

31. Hofmann C, Dunger N, Scholmerich J, Falk W, Obermeier F. Glycogen synthase kinase 3-beta: a master regulator of toll-like receptor-mediated chronic intestinal inflammation. Inflamm Bowel Dis. 2010; 16:1850-8. [PubMed: 20848477]

32. Martin M, Rehani K, Jope RS, Michalek SM. Toll-like receptormediated cytokine production is differentially regulated by glycogen synthase kinase 3. Nat Immunol. 2005; 6:777-84. [PubMed: 16007092]

33. Medzhitov R, Preston-Hurlburt P, Janeway CA Jr. A human homologue of the Drosophila Toll protein signals activation of adaptive immunity. Nature. 1997; 388:394-7. [PubMed: 9237759]

34. Burdelya LG, Krivokrysenko VI, Tallant TC, Strom E, Gleiberman AS, Gupta D, et al. An agonist of toll-like receptor 5 has radioprotective activity in mouse and primate models. Science. 2008; 320:226-30. [PubMed: 18403709]

35. Shakhov AN, Singh VK, Bone F, Cheney A, Kononov Y, Krasnov P, et al. Prevention and mitigation of acute radiation syndrome in mice by synthetic lipopeptide agonists of toll-like receptor 2 (TLR2). PloS ONE. 2012; 7:e33044. [PubMed: 22479357]

36. Saha S, Bhanja P, Liu L, Alfieri AA, Yu D, Kandimalla ER, et al. TLR9 agonist protects mice from radiation-induced gastrointestinal syndrome. PLoS ONE. 2012; 7:e29357. [PubMed: 22238604] 


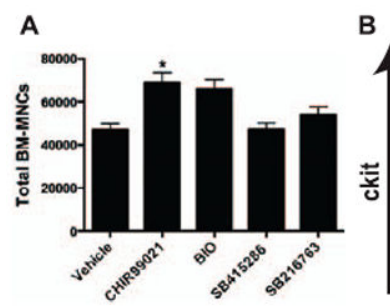

B
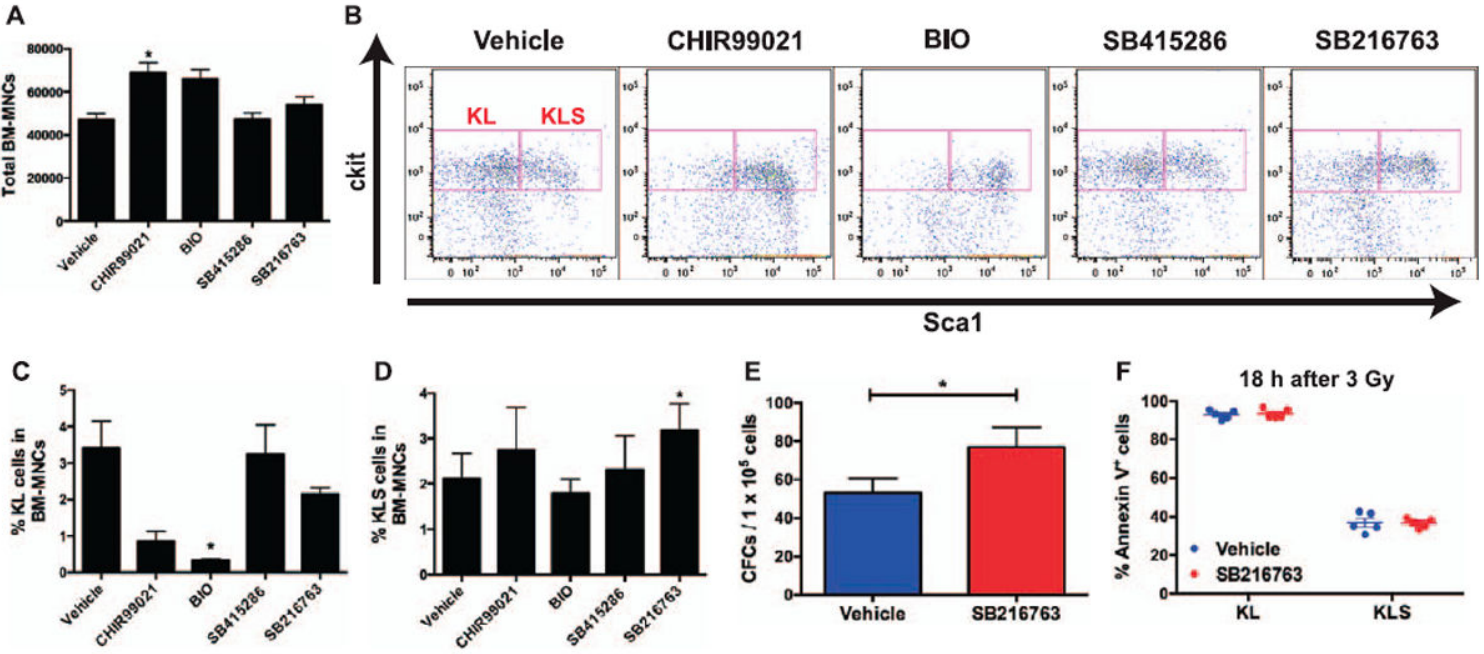

E
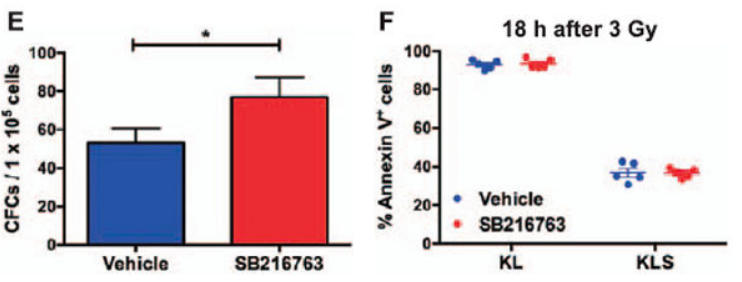

FIG. 1.

An in vitro GSK-3 inhibitor screen using irradiated bone marrow mononuclear cells shows that SB216763 expands hematopoietic progenitors. Bone marrow mononuclear cells (BM$\mathrm{MNCs}$ ) isolated from C57BL/6J mice were cultured in vitro and exposed to $3 \mathrm{~Gy} \gamma$ rays. One hour after irradiation, BM-MNCs were treated with vehicle or the indicated GSK-3 inhibitor $(1 \mu M)$. Panel A: Total live cell count of BM-MNCs cultured in vitro for 7 days after $3 \mathrm{~Gy}$ irradiation. Panel B: Representative flow cytometry dot plots of c-Kit ${ }^{+} \mathrm{Lin}^{-}$ $\mathrm{Sca}^{-}(\mathrm{KL})$ and c-Kit ${ }^{+} \mathrm{Lin}^{-} \mathrm{Sca}^{+}$(KLS) cells. Sca1 and c-Kit were gated on $\mathrm{Lin}^{-}$cells. Panels C and D: Frequencies of KL and KLS cells in BM-MNCs cultured in vitro for 7 days after 3 Gy exposure. Panel E: The number of colony-forming cells (CFCs) per $1 \times 10^{5} \mathrm{BM}$ MNCs cultured in vitro for 10 days after 3 Gy exposure. Panel F: Quantification of KL and KLS cell apoptosis $18 \mathrm{~h}$ after exposure to $3 \mathrm{~Gy}$ by Annexin-V and 7-AAD staining. Data are presented as mean $\pm \operatorname{SEM}(n=4$ independent experiments). $* P<0.05$ compared to vehicle by Student's $t$ test. 
A

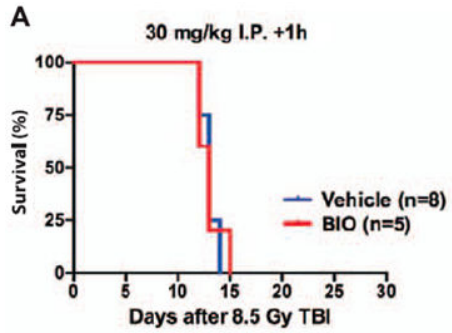

B

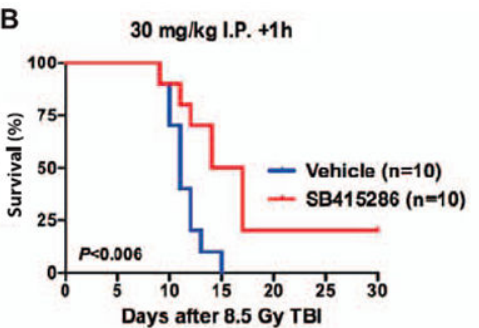

C

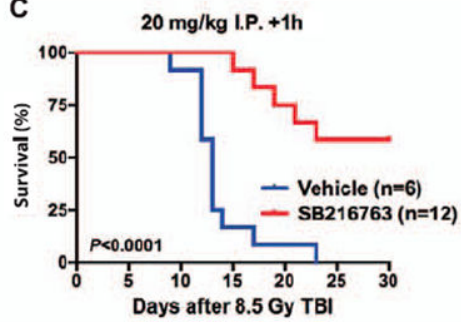

FIG. 2.

SB415286 and SB216763 function after total-body irradiation to mitigate hematopoietic acute radiation syndrome. Overall survival of $\mathrm{C} 57 \mathrm{BL} / 6 \mathrm{~J}$ mice treated with vehicle or the indicated GSK-3 inhibitor after exposure to 8.5 Gy total-body irradiation (TBI) with $\gamma$ rays. Panel A: BIO (30 mg/kg); panel B: SB415286 (30 mg/kg); panel C: SB216763 (20 mg/kg) was administered by intraperitoneal injection (i.p.) $1 \mathrm{~h}$ after TBI. $P$ value was calculated by log-rank test. 
A

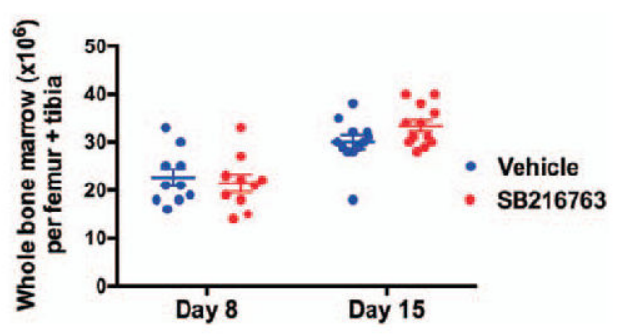

B

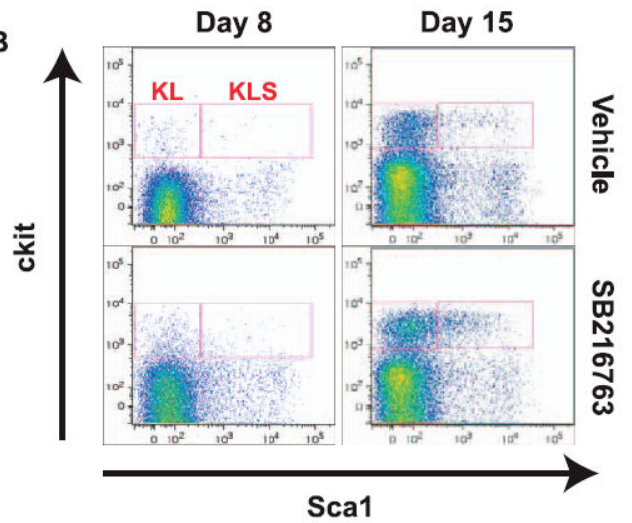

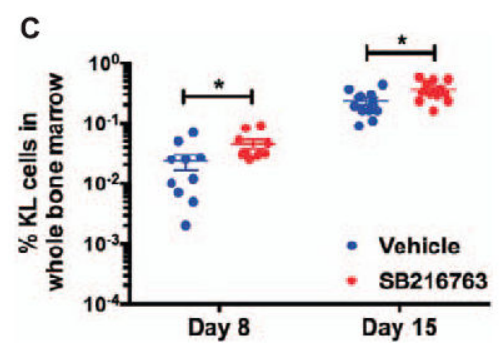
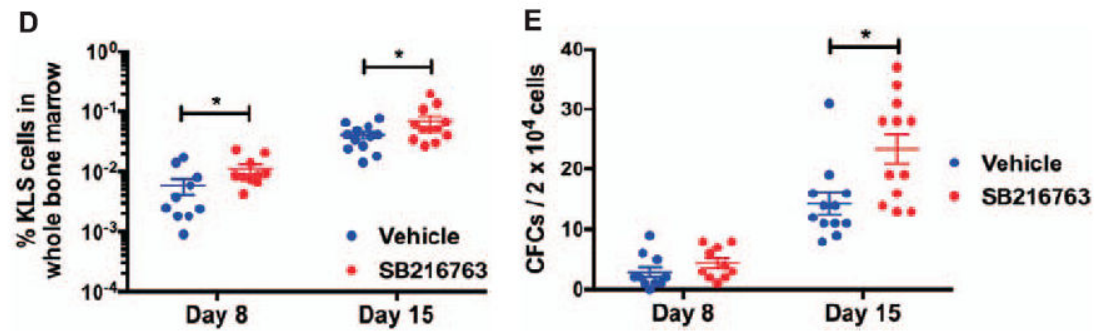

FIG. 3.

Subcutaneous administration of SB216763 $24 \mathrm{~h}$ after total-body irradiation (TBI) improves repopulation of hematopoietic stem/progenitors in the bone marrow. C57BL/6J mice were total-body X irradiated with $5 \mathrm{~Gy}$. Twenty-four hours after TBI, mice were treated with either vehicle or SB216763 $(20 \mathrm{mg} / \mathrm{kg})$ by subcutaneous injection. Panel A: The total cell count of whole bone marrow cells per limb on days 8 and 15 after irradiation. Panel B: Representative flow cytometry dot plots of c-Kit ${ }^{+} \mathrm{Lin}^{-} \mathrm{Sca}^{-}$(KL) and c-Kit ${ }^{+} \mathrm{Lin}^{-} \mathrm{Sca}^{+}$ (KLS) cells. Sca1 and c-Kit were gated on $\mathrm{Lin}^{-}$cells. Panels $\mathrm{C}$ and D: The frequencies of KL and KLS cells in whole bone marrow cells on days 8 and 15 after irradiation. Panel E: The number of colony-forming cells per $2 \times 10^{4}$ whole bone marrow cells on days 8 and 15 after irradiation. Data are shown as mean \pm SEM (each dot represents one mouse). $* P<0.05$ compared to vehicle by Student's $t$ test. 
A

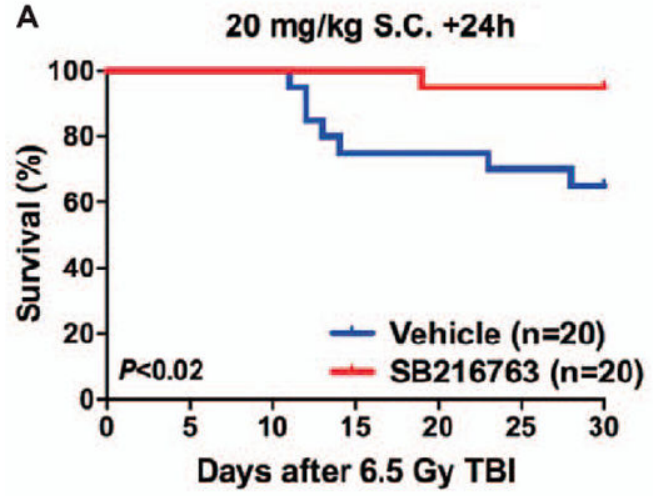

C

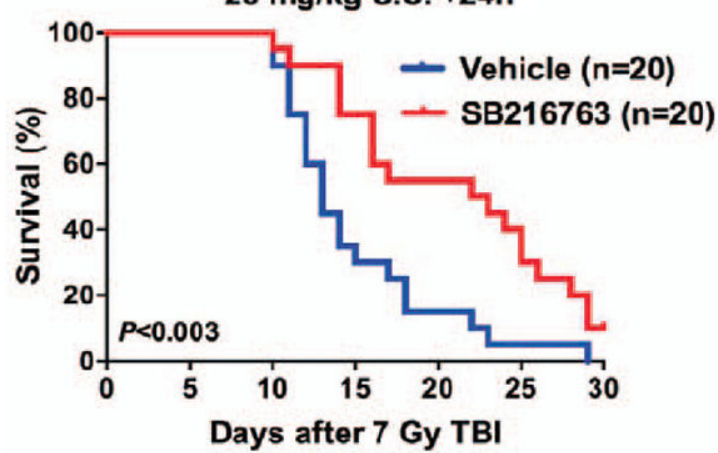

B

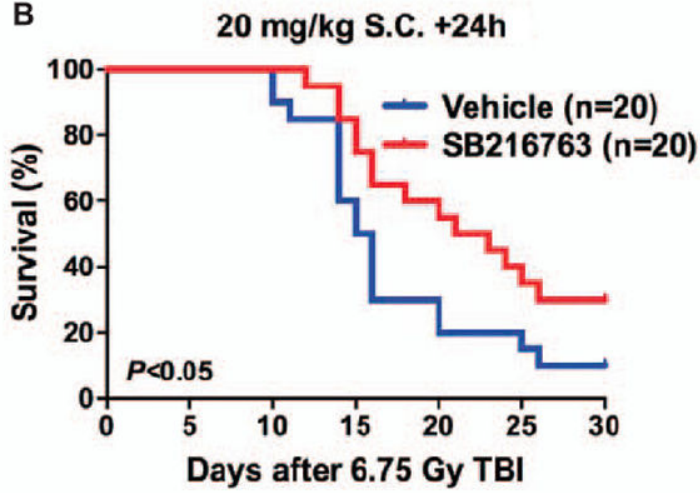

D

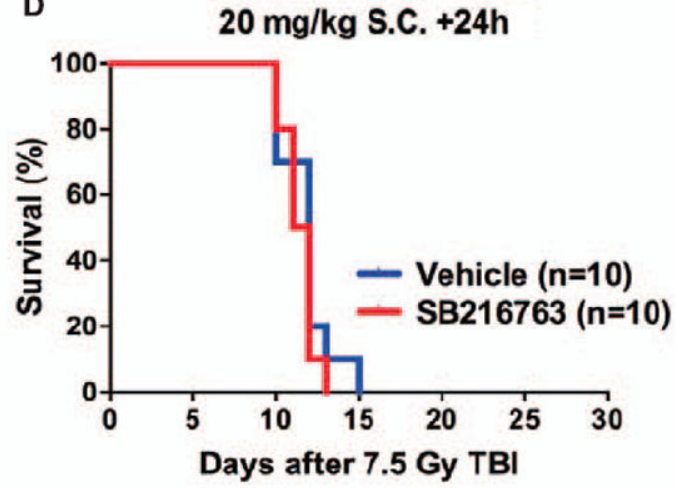

FIG. 4.

SB216763 mitigates hematopoietic acute radiation syndrome when subcutaneously administered $24 \mathrm{~h}$ after total-body irradiation. C57BL/6J mice (50/50 male/female) were randomly allocated to receive either vehicle or $20 \mathrm{mg} / \mathrm{kg} \mathrm{SB} 216763$ by subcutaneous (s.c.) injection $24 \mathrm{~h}$ total-body X irradiation after 6.5 (panel A), 6.75 (panel B), 7 (panel C) or 7.5 Gy (panel D). Mice were followed for the development of the hematopoietic acute radiation syndrome for 30 days after TBI. $P$ value was calculated by log-rank test. 